\title{
Tumor Necrosis Factor-Induced Neonatal Pulmonary Hypertension: Effects of Dazmegrel Pretreatment
}

\author{
W. E. TRUOG, R. L. GIBSON, JR., W. R. HENDERSON, AND G. J. REDDING \\ Departments of Pediatrics and Medicine, University of Washington School of Medicine, \\ Seattle, Washington 98195
}

\begin{abstract}
The endogenously produced cytokine, tumor necrosis factor- $\alpha$ (TNF- $\alpha$ ), has been shown in adult animal models to be associated with many of the pathophysiologic effects of sepsis, including systemic hypotension and hemorrhagic necrosis. TNF- $\alpha$ can induce the release of various vasoactive arachidonic acid metabolites, suggesting that TNF- $\alpha$ may act either directly or via intermediary substances in producing its effects. The pathophysiologic role of TNF- $\alpha$ in neonatal sepsis, especially its potential effect on pulmonary vascular tone, is presently unknown. To assess the role of TNF- $\alpha$ in neonatal sepsis, 19 piglets (19 $\pm 5 \mathrm{~d}$ old) were anesthetized, intubated, paralyzed, mechanically ventilated, and catheterized to assess pulmonary and systemic vascular hemodynamics and pulmonary gas exchange. The multiple inert gas elimination technique was used to assess ventilation perfusion matching. A 30-min infusion of human recombinant TNF- $\alpha(250 \mu \mathrm{g} / \mathrm{kg}$ total dose) was administered to animals pretreated with either $10 \mathrm{mg} / \mathrm{kg}$ dazmegrel, a thromboxane synthase inhibitor ( $n$ $=9)$ or placebo $(n=10)$. TNF- $\alpha$ alone induced a prompt and sustained rise in pulmonary arterial pressure and pulmonary vascular resistance that continued at least for $\mathbf{2 h}$ after onset of the infusion. In contrast, the animals pretreated with dazmegrel demonstrated no rise in pulmonary vascular resistance until $2 \mathrm{~h}$ after the onset of the infusion. Neither group of animals demonstrated a significant decline in arterial $\mathrm{PO}_{2}$ or evidence from inert gas analysis of $\dot{\mathrm{V}}_{\mathrm{A}} / \dot{\mathrm{Q}}$ mismatching or increase in intrapulmonary shunt. We conclude that human recombinant TNF- $\alpha$ induces an acute and sustained elevation in Ppa and PVR without the concomitant development of hypoxemia or intrapulmonary shunt. The pulmonary hypertension is blocked acutely by the putative $\mathbf{T x A}_{2}$ synthase inhibitor, dazmegrel. (Pediatr Res 27: 466-471, 1990)
\end{abstract}

\section{Abbreviations}

Ppa, pulmonary arterial pressure

PVR, pulmonary vascular resistance

Q̀p, pulmonary blood flow

rTNF- $\alpha$, human recombinant tumor necrosis factor $\alpha$

$\dot{\mathbf{V}}_{\mathrm{A}} / \dot{\mathrm{Q}}$, ventilation perfusion ratio

$\mathrm{TxB}_{2}$, thromboxane $\mathrm{B}_{2}$

GBS, group B streptococcus

Pcw, capillary wedge pressure

Psa, systemic arterial pressure

Paw, positive airway pressure

Received July 10, 1989; accepted December 13, 1989

Correspondence: William E. Truog, M.D., Department of Pediatrics RD-20, University of Washington School of Medicine, Seattle, WA 98195.

Supported in part by NIH Institutes of Health Grants HL19187, HL30542 (W.R.H.), and HL01205 (W.E.T.), and in part by RJR Nabisco Pulmonary Research Scholar Award (R.L.G.).
PIM, pulmonary intravascular macrophage PG, prostaglandin

Experimental sepsis (1) or endotoxin $(2,3)$ administration increases both Ppa and PVR. Increased Ppa and PVR can promote or inhibit efficient $\dot{V}_{A} / \dot{Q}$ matching by altering $\dot{Q} p$ distribution. In neonatal animals, (GBS)-induced increase in PVR is associated with immediate and sustained hypoxemia (4 5). The arachidonate metabolite $\mathrm{TxA}_{2}$ is associated with an increase in PVR acutely after the onset of neonatal experimental GBS or other gram-positive sepsis $(6,7)$. Use of the Tx synthase inhibitor dazmegrel blunts pulmonary hypertension occurring both with onset of GBS infusion (6) and when used after $2 \mathrm{~h}$ of infusion (8), but fails to reverse the hypoxemia in the latter situation (8). The role of other vasoactive agents in both the immediate and later phases of neonatal sepsis is unknown. The vasoactive cytokine, TNF- $\alpha$, a 157 amino acid polypeptide synthesized and released by mononuclear phagocytes, induces many signs of sepsis in adult animals models (9). In addition, TNF- $\alpha$ in vitro induces release of vasoactive arachidonate metabolites including $\mathrm{TxB}_{2}(10)$. The adverse effects of TNF- $\alpha$ infusion have been prevented by pretreatment with the cyclooxygenase inhibitor indomethacin (11). Specific inhibitors of $\mathrm{TxA}_{2}$ formation have not been assessed during TNF- $\alpha$ induced disease.

We used the vigorous and reproducible pulmonary vasoconstrictive response found in the neonatal piglet $(5,12)$ to test the hypothesis that infusion of TNF- $\alpha$ would induce an increase in Ppa and PVR associated with a concomitant deterioration in pulmonary gas exchange. We further hypothesized that the pulmonary hemodynamic alteration induced by TNF- $\alpha$ would be prevented by pretreatment with the specific thromboxane synthase inhibitor, dazmegrel, (UK 38,485).

\section{MATERIALS AND METHODS}

Animal preparation. Nineteen piglets $[19 \pm 5 \mathrm{~d}$ of age and 3.5 $\pm 0.4 \mathrm{~kg}$ (mean $\pm \mathrm{SD})]$ were anesthetized with $35-40 \mathrm{mg} / \mathrm{kg}$ i.v. pentobarbital and also received $200 \mathrm{U} / \mathrm{kg}$ of heparin. They were mechanically ventilated via a metal tracheostomy tube at a tidal volume of $12 \pm 2 \mathrm{~mL} / \mathrm{kg}$ at a rate that maintained arterial $\mathrm{PCO}_{2}$ at approximately $40 \pm 5$ torr $(5.1 \pm 1 \mathrm{kPa})$. Animals were paralyzed with $0.3 \mathrm{mg} / \mathrm{kg}$ pancuronium bromide intravenously; anesthesia and paralysis were maintained for the duration of the experiment with administration of $5 \mathrm{mg} / \mathrm{kg}$ of pentobarbital and $0.3 \mathrm{mg} / \mathrm{kg}$ of pancuronium as needed. Body temperature was monitored with a rectal probe (Yellow Springs Instrument Co., Yellow Springs, $\mathrm{OH}$ ) and maintained with a heat lamp at a temperature of $38.5 \pm 0.5^{\circ} \mathrm{C}$.

A no. 5 FR thermodilution balloon-tipped catheter was placed 
in the pulmonary artery using fluoroscopic monitoring. This catheter was used to measure continuously Ppa and intermittently measure Pcw, $\dot{Q} p$, and to withdraw samples for mixed venous blood gas tensions and $\mathrm{pH}$. A catheter was placed in the ascending aorta via the internal carotid artery to measure continuously Psa and to obtain blood for arterial blood gas tensions and $\mathrm{pH}$. A double lumen catheter was inserted into a peripheral vein for continuous drug infusion. Expiratory tidal volume and respiratory frequency were measured by placing a pneumotachograph (Fleisch 00) (DynaSciences, Blue Bell, PA) in the expired gas stream just distal to a one-way valve on the expiratory side of a ventilator circuit (13). Paw was measured continuously at the proximal tracheostomy port. All vascular and airway pressures were measured with Statham $\mathrm{P} 23 \mathrm{Db}$ transducers, averaged to obtain mean values, and continuously recorded (Hewlett Packard 7758B multichannel recorder, Waltham, MA). Phasic pressure recordings were used to monitor heart rate. Pressures were recorded only during expiration. Pulmonary blood flow was measured by thermodilution technique. Three measurements using an Edwards $9520 \mathrm{~A}$ cardiac output computer (American Edwards Laboratory, Irvine, CA) under each experimental condition were obtained and averaged. If the values varied by more than $10 \%$, additional measurements were obtained. Blood gas tensions, $\mathrm{pH}$, and inspired gas partial pressures were determined using a Corning $168 \mathrm{pH}$ blood gas analyzer (Corning Medical, Medfield, MA). Samples were measured within 3 min of collection. An index of pulmonary vascular resistance was calculated from the formula: PVR $=\mathrm{Ppa}-\mathrm{Pcw} \div$ by Qp. Animals were ventilated with room air during the experiment.

$T N F$ preparation. TTNF- $\alpha$, derived from Escherichia coli, was kindly supplied as a gift from Knoll Pharmaceutical Co. (Whippany, NJ). The material was supplied as a lyophilized powder; each glass vial contained $0.98 \mathrm{mg} \mathrm{rTNF}-\alpha$. The vials were kept frozen $\left(-70^{\circ} \mathrm{C}\right)$ until the day of each experiment. The material was reconstituted to $100 \mu \mathrm{g} / \mathrm{mL}$ with sterile water containing 0.5 $\mathrm{g} / 100 \mathrm{~mL}$ human serum albumin. Only glass syringes were used for reconstitution and administration, as rTNF- $\alpha$ adheres less to glass than to plastic.

Limulus amebocyte lysate assay (Pyrotell, Associates of Cape Cod, Inc., Woods Hole, MA) was performed on one vial to detect any endotoxin present with the rTNF- $\alpha$. A concentration between 6 and $60 \mathrm{pg}$ endotoxin/mg rTNF- $\alpha$ was detected. To eliminate the possibility that this amount of endotoxin infused with the rTNF- $\alpha$ affected Ppa and PVR, piglets of the same age as the study animals received a $30-\mathrm{min}$ infusion of $E$. coli lipopolysaccharide 055:0B5 (Sigma Chemical Co., St. Louis, $\mathrm{MO}$ ) in total dosages ranging between 30 and $500 \mathrm{pg}$. No change in Ppa, PVR, Qp, Psa, or arterial blood gas tensions was detected with these doses during the infusion period or for $2.0 \mathrm{~h}$ afterward.

Dazmegrel preparation. Dazmegrel (UK 38,485), kindly supplied as a gift from Pfizer Pharmaceuticals, (Groton, CT) was administered in an $8-10 \mathrm{mg} / \mathrm{kg}$ dose. The material was supplied as a powder, and was dissolved just before infusion in $1.0 \mathrm{~mL}$ of $0.1 \mathrm{~N} \mathrm{NaOH}$, to which was added $4.0 \mathrm{~mL} 0.9 \%$ saline. Dazmegrel was then infused i.v. over a period of $5 \mathrm{~min}$.

Assessment of ventilation perfusion matching. The multiple inert gas elimination technique $(14,15)$ was used to assess intrapulmonary shunt and distribution of $\dot{\mathrm{V}}_{\mathrm{A}} / \dot{\mathrm{Q}}$ ratios. The technique requires continuous intravenous infusion of six inert gases (sulfur hexaflouride, ethane, cyclopropane, halothane, diethyl ether, and acetone) dissolved in $0.9 \%$ saline with $5 \%$ dextrose $(5 \mathrm{~mL} / \mathrm{kg} / \mathrm{h})$. Simultaneous sampling of pulmonary arterial and systemic arterial blood $(4 \mathrm{~mL})$ and mixed expired gas $(20 \mathrm{~mL})$ was then performed. The expired gas sample was obtained in a heated syringe to avoid condensation of water vapor in the expired gas and loss of soluble expired inert gases into the water vapor. Samples were then analyzed using a gas chromatograph and an electron-capture detector to measure relative concentration of each of the six inert gases in each sample.
Intrapulmonary shunt, defined as percent perfusion to areas of zero ventilation, and a unitless index of ventilation-perfusion heterogeneity separate from shunt and dead space, the SD of perfusion $(8,16)$, were used as indices of $\dot{V}_{A} / \dot{Q}$ matching. Special care was taken to maintain constant hematocrit and temperature during the experimental protocol to avoid fluctuations in the blood gas partition coefficient during the experiment (17).

Measurement of plasma thromboxane $B_{2}$. RIA was performed for measurement of $\mathrm{TxB}_{2}$, the stable breakdown product of $\mathrm{TxA}_{2}$, on arterial plasma samples obtained at baseline and at the end of the rTNF- $\alpha$ infusion. The details of the methodology used in our laboratory have been previously published (8). In brief, at each sampling time, a 2-mL sample of arterial blood was obtained by drawing the blood through a short plastic catheter directly into previously prepared fresh, cold inhibitor solution containing indomethacin and sodium EDTA. Samples were kept in an ice bath until centrifugation $\left(15000 \mathrm{rpm} \times 15 \mathrm{~min}\right.$ at $\left.4.0^{\circ} \mathrm{C}\right)$. Plasma was decanted, frozen, and stored at $-70^{\circ} \mathrm{C}$. until RIA was performed. Samples were then analyzed in duplicate according to standard protocol $(18,19)$. No matrix effects due to protein present in unknown piglet plasma samples were found when standard curves run with eicosanoid-free piglet plasma prepared by charcoal stripping were compared to curves generated from samples not treated with charcoal. The antibody against $\mathrm{TxB}_{2}$ that was employed in the RIA was produced in our laboratory and had a sensitivity of $1 \mathrm{pg} / 0.1 \mathrm{~mL}$ sample at a dilution of 1:100 000 (19). The cross-reactivities of this anti- $\mathrm{TxB}_{2}$ antiserum have been published previously $(8,19)$.

Experimental protocol. After the instrumentation and preparation, baseline data were obtained to confirm that the animals met minimal criteria for further investigation. Criteria included absence of metabolic acidosis, (calculated base deficit $\leq-9 \mathrm{mEq}$ / L) arterial $\mathrm{pH} \geq 7.35$, arterial $\mathrm{PO}_{2} \geq 70$ torr $(9 \mathrm{kPa})$ during room air ventilation, and systemic arterial blood pressure $>60$ torr $(8$ $\mathrm{kPa}$ ). Three animals from an original group of 22 were rejected based on these criteria; the 19 remaining animals form the basis of this report.

Once baseline data, including blood samples for respiratory and inert gas analysis and for $\mathrm{TxB}_{2}$ assay were collected, the animals were randomized to receive either dazmegrel (nine animals) or no pretreatment (10 animals). Infusion of the carrier substance for dazmegrel has been previously shown to have no cardiovascular effects on similar aged piglets (6).

Twenty min after the dazmegrel administration to animals assigned to the dazmegrel group, a second set of samples was obtained. After this new baseline evaluation, animals in both groups received a continuous intravenous infusion of $\mathrm{rTNF}-\alpha$. A total of $0.98 \mathrm{mg}$ rTNF- $\alpha$ was administered during the $30-\mathrm{min}$ period. In the dazmegrel pretreated animals, if no change in pulmonary artery pressure was detected at the initial infusion dosage, the rTNF- $\alpha$ dose was briefly doubled to attempt to elicit any change in Ppa at the higher dose. No change in Ppa was noted.

Systemic and pulmonary arterial pressures were monitored continuously throughout the infusion. Hemodynamic measurements were monitored continuously and recorded $20 \mathrm{~min}$ after the initiation of the rTNF- $\alpha$ infusion. Blood for repeat $\mathrm{TxB}_{2}$ assay was obtained at the end of the rTNF- $\alpha$ infusion $(30 \mathrm{~min}$ ).

Statistical analysis. Analysis of variance was performed to determine if there were any significant changes in mean values for gas exchange or PVR at each experimental time point within each group. If so, a paired $t$ test was used with correction for multiple comparisons (20) to determine if any of the experimental values differed from the baseline for each group of piglets. Between group comparisons were made with the unpaired $t$ test. Data are expressed as the mean and SD of each group of animals.

\section{RESULTS}

Effect of $r T N F-\alpha$ on pulmonary hemodynamics. The rTNF- $\alpha$ infusion produced an immediate rise in Ppa (Fig. 1) and PVR 


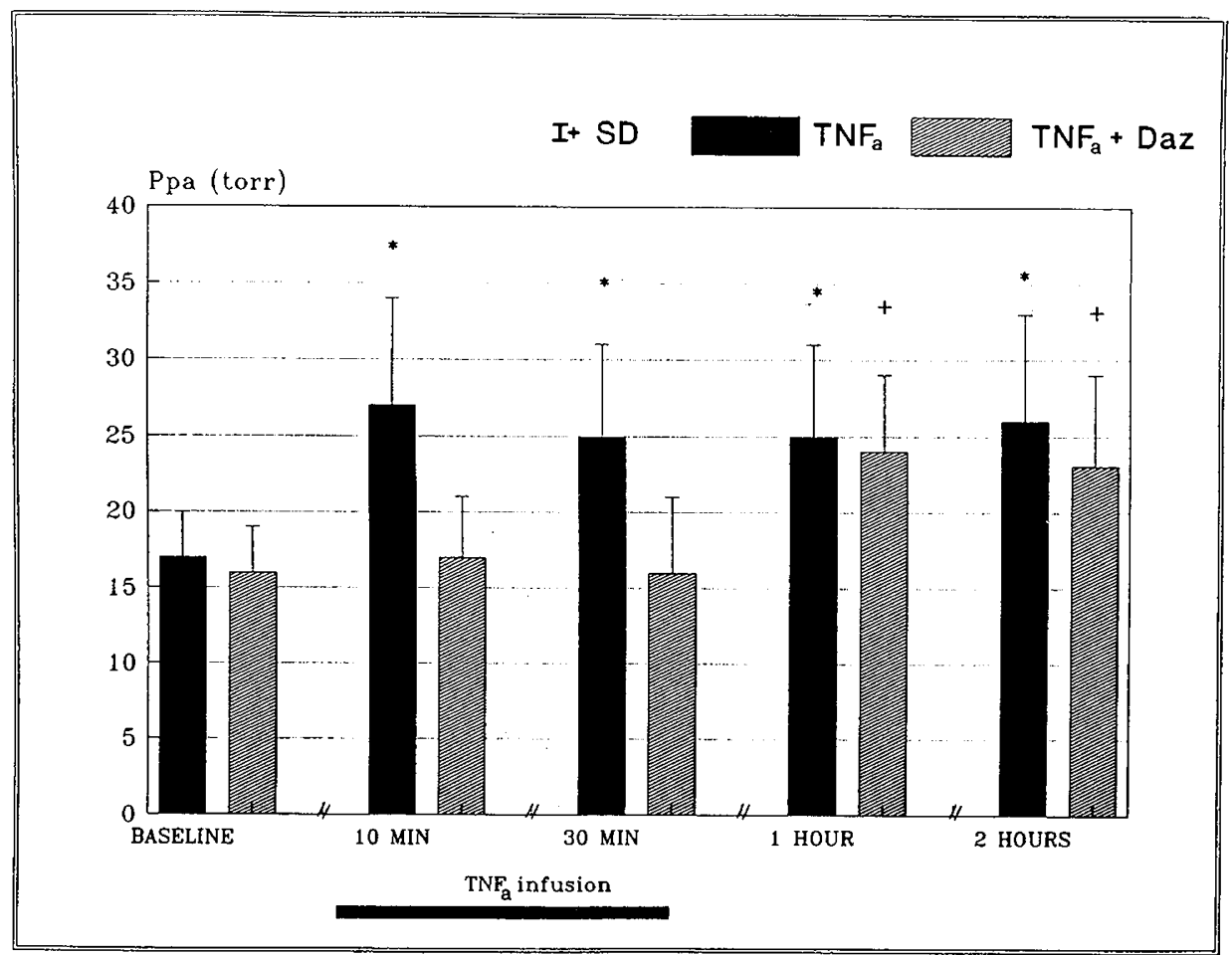

Fig. 1. Ppa plotted against experimental timepoints. Solid line below abscissa shows the duration of the rTNF- $\alpha$ infusion. rTNF- $\alpha$ induced an acute increase in Ppa in nonpretreated animals compared to the baseline values for that group. Dazmegrel pretreated animals demonstrated no response to rTNF- $\alpha$ until 2 h. ${ }^{*} p<0.01+p<0.02$ compared to baseline for each group. Note: 40 torr $=5.1 \mathrm{kPa}$.

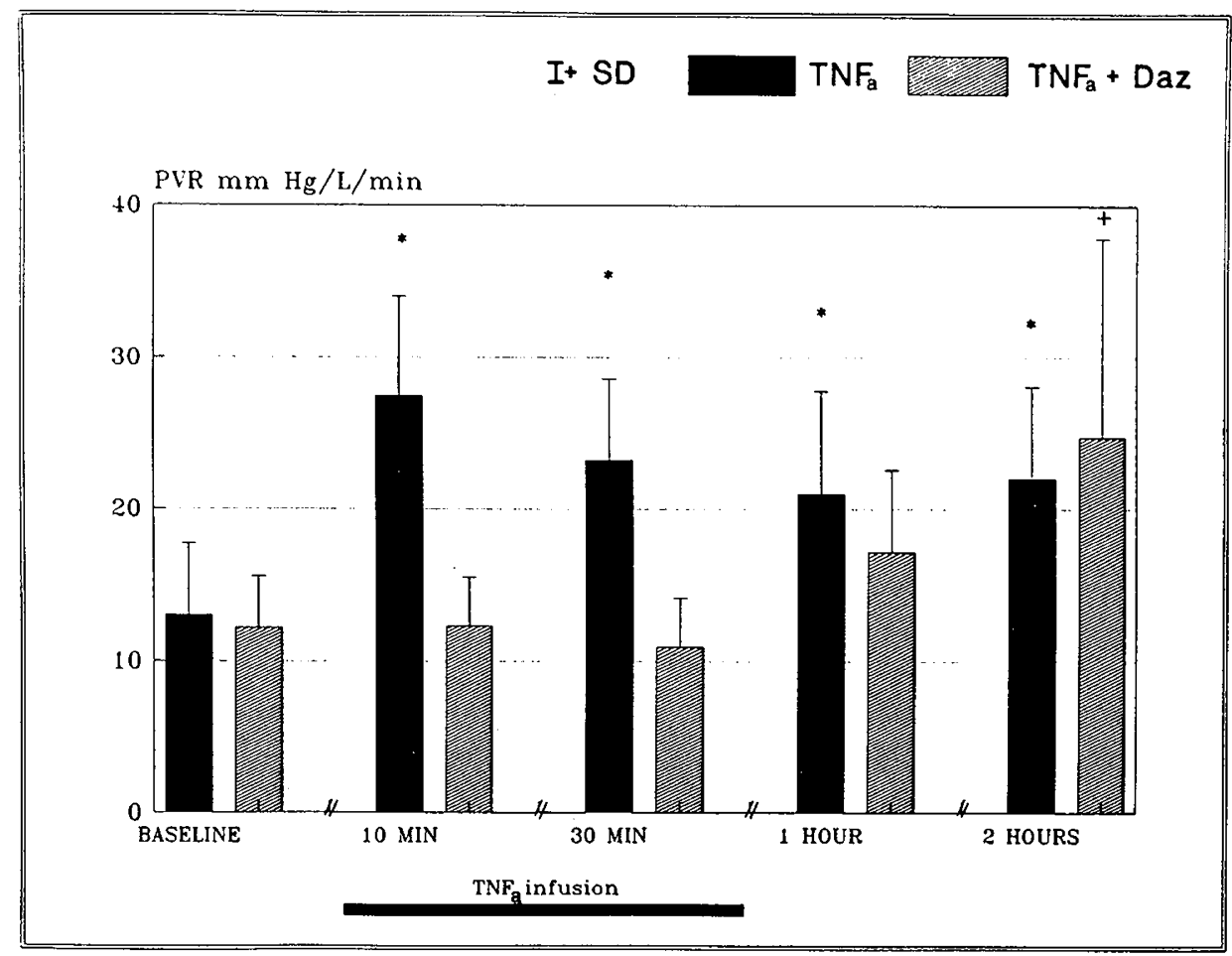

Fig. 2. PVR is plotted against experimental conditions. rTNF- $\alpha$ induced an acute increase in PVR in non-pretreated animals compared to the baseline values for that group. Dazmegrel pretreated animals demonstrated no response to rTNF- $\alpha$ until 2 h. ${ }^{*} p<0.01,+p<0.02$ compared to baseline for each group.

(Fig. 2) in the nonpretreatment group. The increases were sustained throughout the remainder of the experimental time period, including up to $2 \mathrm{~h}$ after onset of infusion, compared to baseline data. In contrast, when compared to baseline data, no significant effect in the dazmegrel-pretreated group was noted on Ppa until $1 \mathrm{~h}$ after onset of infusion, and on calculated PVR until $2 \mathrm{~h}$, by which time the mean PVR was equal between the two groups.

$\dot{Q}$ p, plotted against time of the experiment, is shown in Figure 3. There was no significant decrease until $2 \mathrm{~h}$, compared to baseline for each group. Baseline Q́p did not differ between the two groups. 


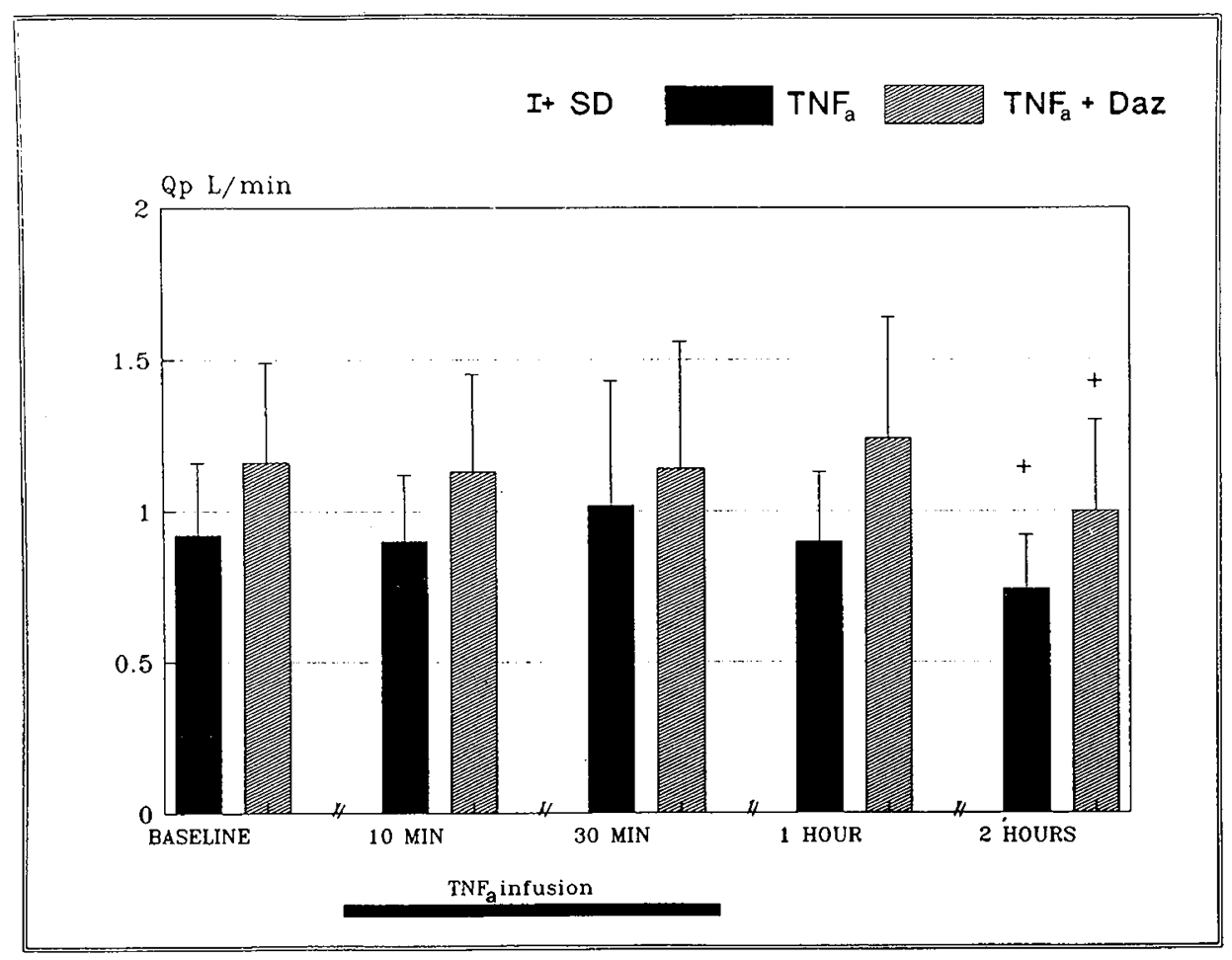

Fig. 3. Q $\mathrm{p}$ is plotted against experimental time points. In neither group was there a significant change in mean pulmonary blood flow at any point in the experiment until $2 \mathrm{~h}$ when there was a statistically significant decrease in both groups in Qp compared to baseline for each group. $+p$ $<0.02$, compared to baseline for each group.

Effect of $r T N F-\alpha$ on gas exchange. The elevation of Ppa and PVR was not associated with deterioration in pulmonary gas exchange as assessed by arterial $\mathrm{PO}_{2}$, by change in percent shunt or mismatching of ventilation perfusion as assessed by low $\dot{V}_{A} /$ $\dot{Q}$ area or SD or perfusion when these data were compared to baseline for each group (Table 1). Arterial $\mathrm{pH}$ and $\mathrm{PCO}_{2}$ did not change during the period of time studied in each group. The mean arterial $\mathrm{pH}$ for each group ranged between 7.43 and 7.35 at the experimental times. Mean airway pressure also did not change with the rTNF- $\alpha$ infusion.

Effect of $r T N F-\alpha$ on systemic blood pressure. Mean Psa is shown for both groups (Table 2). Only at $2 \mathrm{~h}$ postinfusion was there a significant but still modest decline in mean systemic pressure in each of the groups of animals compared to baseline data. There was no change in mean heart rate during the experimental period in either group compared to baseline values.

Effect of $r T N F_{-\alpha}$ on $T x B_{2}$. Results of baseline and $30-\mathrm{min}$ arterial plasma $\mathrm{TxB}_{2}$ levels are shown (Fig. 4). Although there was a trend toward increased $\mathrm{TxB}_{2}$ at $30 \mathrm{~min}$ after initiation of the infusion of rTNF- $\alpha$, the mean increase of $80 \%$ above baseline was not statistically significant because of the large variability of $\mathrm{TxB}_{2}$ values in the rTNF- $\alpha$-treated group. There was no correlation between magnitude of increase in PVR and absolute or percent rise in $\mathrm{TxB}_{2}$ from baseline to $30 \mathrm{~min}$ in this group. No trend toward rising $\mathrm{rTNF}-\alpha$ levels was detected in the dazmegrelpretreated animals between the baseline and 30-min measure- ment points (Fig. 4). Mean values for baseline plasma $\mathrm{TxB}_{2}$ in the two groups were not significantly different.

\section{DISCUSSION}

Infusion of rTNF- $\alpha$ resulted in a $220 \%$ increase in PVR by 10 min and an approximately $100 \%$ increase for the remainder of the acute experimental period. These results may represent the minimal vasoactive effect of TNF- $\alpha$. We have preliminary evidence that there is significant homology between porcine and human TNF- $\alpha$ (Gibson RL, unpublished observations). The dosage of rTNF- $\alpha$ used in the present experiment was based on pilot studies. Those studies demonstrated that a 3-fold higher infusion rate resulted in systemic hypotension and bradycardia. By contrast, pilot study dosage levels of 0.1 to 0.3 of the present dose produced no detectable change in Ppa, at least during a 30min infusion. Dazmegrel, an advanced form imidazole inhibitor of the enzyme $\mathrm{TxA}_{2}$ synthase (21), blocks thromboxane $\mathrm{A}_{2}$ production without affecting the synthesis of intermediary products in the arachidonate metabolite pathway (21). The dosage of dazmegrel used in our study was similar to that used in previous studies examining neonatal group B streptococcal sepsis (6) and endotoxin-induced shock (22), in which dazmegrel abrogated acute elevations in plasma $\mathrm{TxB}_{2}$ levels (6). Dosage of dazmegrel was similar to that used by others to achieve complete $\mathrm{TxA}_{2}$ synthase inhibition in vivo (22).

Table 1. Effects on gas exchange (mean $\pm 1 S D)$

\begin{tabular}{|c|c|c|c|c|c|c|c|c|}
\hline & \multicolumn{4}{|c|}{ TNF $(n=10)$} & \multicolumn{4}{|c|}{ TNF plus dazmegrel $(n=9)$} \\
\hline & Baseline & $30 \mathrm{~min}$ & $1 \mathrm{~h}$ & $2 \mathrm{~h}$ & Baseline & $30 \mathrm{~min}$ & $1 \mathrm{~h}$ & $2 \mathrm{~h}$ \\
\hline Arterial $\mathrm{PO}_{2} *$ (torr) & $86 \pm 10$ & $79 \pm 13$ & $80 \pm 11$ & $82 \pm 9$ & $86 \pm 6$ & $80 \pm 8$ & $78 \pm 10$ & $76 \pm 10$ \\
\hline Intrapulmonary shunt (\%) & $0.9 \pm 0.8$ & $1.8 \pm 0.2$ & $2.3 \pm 1.0$ & $2.2 \pm 1.0$ & $0.4 \pm 0.5$ & $0.9 \pm 0.9$ & $1.6 \pm 1.2$ & $2.2 \pm 1.0$ \\
\hline SDQp $\dagger$ (unitless) & $0.73 \pm 0.26$ & $0.77 \pm 0.17$ & $0.74 \pm 0.24$ & $0.86 \pm 0.14$ & $0.74 \pm 0.19$ & $0.80 \pm 0.21$ & $0.80 \pm 0.17$ & $0.88 \pm 0.18$ \\
\hline
\end{tabular}

* Note: 100 torr $=12.9 \mathrm{kPa}$.

$\uparrow$ See text for derivation. 
Table 2. Effect on systemic mean arterial pressure (mean $\pm I S D$ )

\begin{tabular}{|c|c|c|c|c|c|c|c|c|}
\hline & \multicolumn{4}{|c|}{ TNF } & \multicolumn{4}{|c|}{ TNF + dazmegrel } \\
\hline & Baseline & $30 \mathrm{~min}$ & $1 \mathrm{~h}$ & $2 \mathrm{~h}$ & Baseline & $30 \mathrm{~min}$ & $1 \mathrm{~h}$ & $2 \mathrm{~h}$ \\
\hline Psa (torr)* & $82 \pm 21$ & $78 \pm 18$ & $74 \pm 18$ & $67 \pm 13 \dagger$ & $85 \pm 8$ & $79 \pm 8$ & $77 \pm 12$ & $56 \pm 18$ \\
\hline
\end{tabular}

* Note: $120 \mathrm{~mm} \mathrm{Hg}=15.4 \mathrm{kPa}$.

$\dagger p<0.02$ compared to baseline.

$\ddagger p<0.01$ compared to baseline.

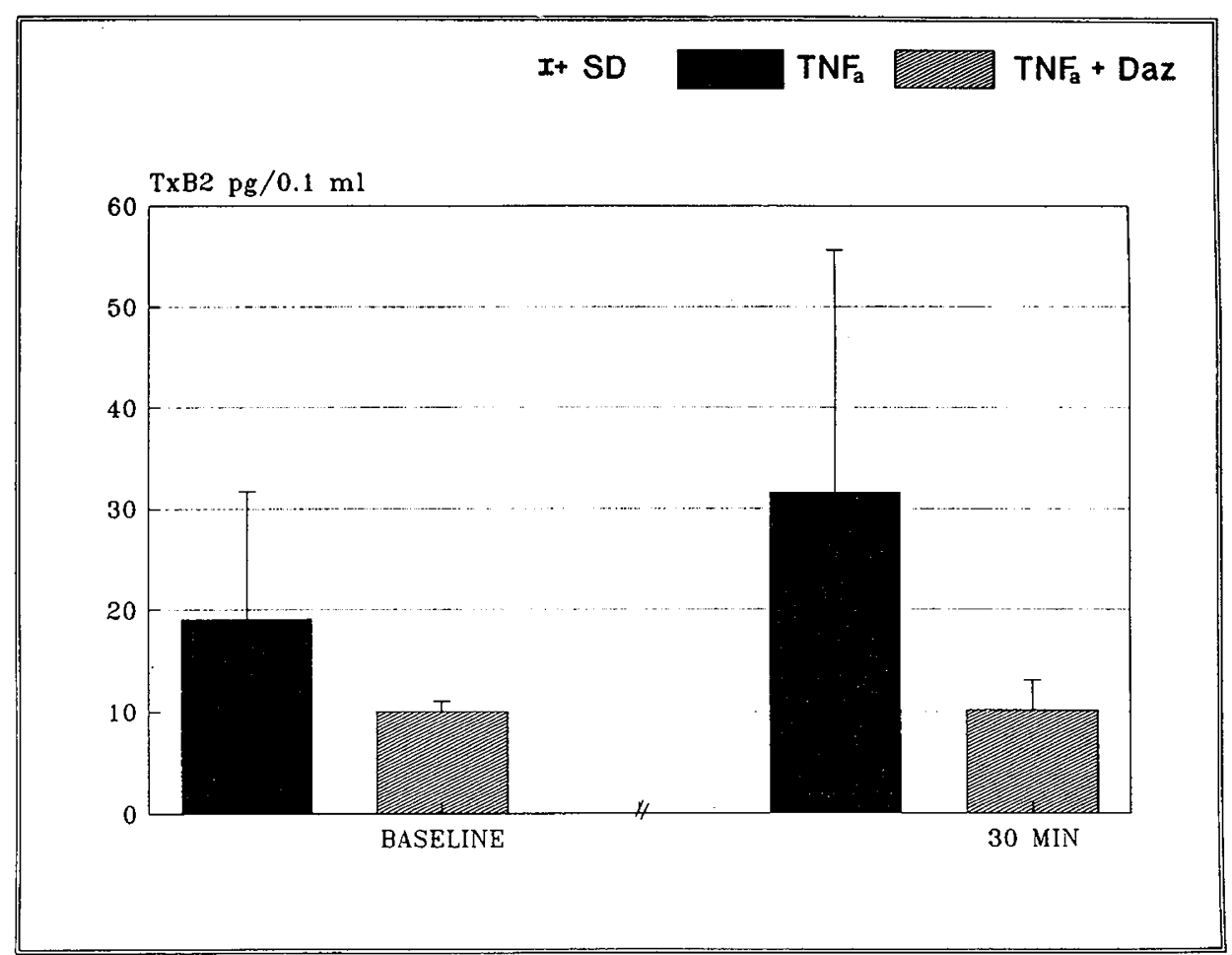

Fig. 4. A plot of mean plasma $\mathrm{TxB}_{2}$ levels obtained at baseline is shown and at the end of the TNF infusion. $r \mathrm{TNF}-\alpha$ infusion was associated with a trend in elevation in plasma levels in the nonpretreated animals $(0.05<p<0.10)$; no trend developed in the dazmegrel-pretreated animals.

The use of $\mathrm{TxB}_{2}$ as an indicator of the synthesis of the vasoconstrictor $\mathrm{TxA}_{2}$ has been criticized because it is a nonenzymatic breakdown product and easily generated in vitro by sample handling (23). However, the relatively low level of $\mathrm{TxB}_{2}$ found in our study during baseline conditions, compared to baseline measurements by others (24) is evidence against inadvertent conversion of $\mathrm{TxA}_{2}$ to $\mathrm{TxB}_{2}$ during specimen handling.

The lung of the neonatal piglet demonstrates several similarities to the lung of the newborn human. There is architectural similarity, characterized by common lack of collateral ventilation, and by common postnatal development of the pulmonary vasculature $(12,25)$. Although both the human and porcine lung may contain PIM, which may participate in the pulmonary vasoconstrictive response (26), including during bacterial infusion (27), there are differences in the number of PIM between species (28). These differences in number of PIM, as well as agedependent pulmonary vascular muscular development, may both be determinants of the pulmonary vascular response to sepsis $(29,30)$. Of interest is that in three pilot studies of rTNF$\alpha$ infusion in piglets $4-7 \mathrm{~d}$ old, a similar pulmonary hypertensive response to a similar dose $/ \mathrm{kg}$ of $\mathrm{rTNF}-\alpha$ was elicited. Our hemodynamic and gas exchange measurements are consistent with findings by others of similarities in piglet lung functional development between 1 and 2 wk of age (31). The postnatal age of the animals in the present study eliminated contribution to Qp from a patent ductus arteriosus (32).

TNF- $\alpha$ induces many of the characteristics of septic shock, including systemic hypotension, disseminated intravascular co- agulation, and multifocal hemorrhagic necrosis $(9,33)$. TNF- $\alpha$ induces pulmonary edema in neutrophil sufficient guinea pigs after i.v. infusion (34). However, effects of TNF- $\alpha$ on Ppa and PVR are not consistent between experiments. Guinea pigs that were infused with TNF- $\alpha$ showed modest and transient elevations in Ppa (34). In contrast, adult sheep demonstrated a marked but also transient pulmonary hypertensive response of rapid onset (35). Both findings are in contrast to our study, which demonstrated acute onset but sustained elevation in pulmonary vascular resistance up to $2 \mathrm{~h}$ after onset of the infusion. It may be that the more vigorous pulmonary vasoconstrictive response to other stimuli noted in neonates of other species (36) was relevant in this animal model.

The mechanism of action of the pulmonary vasoconstriction of $\mathrm{rTNF}-\alpha$ is uncertain. Some of the acute actions of TNF- $\alpha$ are mediated via arachidonate metabolites in adult animal models (11). The same pathways may exist in neonatal animals. TNF- $\alpha$ causes an increase in $\mathrm{TxB}_{2}$ release when incubated with rat peritoneal macrophages and human peripheral blood neutrophils in cell culture (10). TNF- $\alpha$ incubation with monocytes releases platelet-activating factor (37). Some of the septic shock-like effects of TNF- $\alpha$ can be blocked in rats by pretreatment with a cyclooxygenase inhibitor (11). TNF- $\alpha$ is also capable of inducing synthesis of $\mathrm{PGE}_{2}$, a known pulmonary vasodilator (38). In endothelial cell cultures, established with cells obtained from pulmonary artery and lung microvascular endothelial cells, TNF$\alpha$ induced release of both vasodilators $\mathrm{PGE}_{2}$ and $\mathrm{PGI}_{2}$, with $\mathrm{PGE}_{2}$ predominating in the microvascular endothelial cell culture, suggesting a differential site-specific effect of TNF- $\alpha$ (39). 
The results of our study are not completely consistent with $\mathrm{TNF}-\alpha$ inducing and sustaining pulmonary hypertension solely on the basis of $\mathrm{TxA}_{2}$ release. TNF release cannot explain all the pathophysiologic effects previously demonstrated in neonatal piglet models of GBS sepsis $(5,6)$. Thromboxane has been demonstrated to be a pulmonary venoconstrictor and an inducer of pulmonary edema (40). Widespread alveolar pulmonary edema would be expected to interfere with gas exchange, which was not found in these studies. Therefore, it is possible that TNF$\alpha$ fails to stimulate release of some vasoactive factors that may contribute to $\dot{\mathrm{V}}_{\mathrm{A}} / \dot{\mathrm{Q}}$ mismatching; or less likely, that some of the other vasoactive substances that may also be released by TNF- $\alpha$ induction may help preserve pulmonary gas exchange.

The suggestion that TNF- $\alpha$ may be a mediator of pulmonary hypertensive vascular disorders is strengthened by findings that neonatal monocytes are capable of synthesizing and releasing $\mathrm{TNF}-\alpha(41)$, and by the finding that alveolar monocytes produce a greater quantity of TNF- $\alpha$ than circulating peripheral blood monocytes (42).

Our findings, and the demonstration that TNF- $\alpha$ is detectable in large quantities in the plasma of a neonatal animal model of GBS sepsis (43), provide evidence that TNF- $\alpha$ may be an important mediator in pulmonary hypertensive conditions in the neonate.

Acknowledgments. The authors acknowledge the technical support of Richard E. Tuck, James Jordan, and Sue Palmer and the secretarial support of Denise M. Gerdon.

\section{REFERENCES}

1. Rojas B, Green RS, Hellerqvist CG, Olegard R, Brigham KL, Stahlman MT 1981 Studies on group B-hemolytic streptococcus. II. Effects on pulmonary hemodynamics and vascular permeability in unanesthetized sheep. Pediatr Res 15:899-904

2. Harlan J, Winn R, Harker L, Hildebrandt J 1983 Thromboxane $\mathrm{A}_{2}$ inhibits lung vasoconstrictive but not permeability after endotoxin. J Clin Invest 72:911-918

3. Watkins WD, Huttermeier PC, Kong D, Peterson MB 1982 Thromboxane and pulmonary hypertension following $E$. coli endotoxin infusion in sheep: effect of an imidazole derivative. Prostaglandins 23:273-285

4. Runkle B, Goldberg RN, Streitfeld MM, Clar MR, Buron E, Setzer ES, Bancalari E 1984 Cardiovascular changes in group B streptococcal sepsis in the piglet: response to indomethacin and relationship to prostacyclin and thromboxane $\mathrm{A}_{2}$. Pediatr Res 18:874-878

5. Sorenson GK, Redding GJ, Truog WE 1985 Mechanisms of pulmonary gas exchange abnormalities during experimental group B streptococcal infusion. Pediatr Res 19:922-926

6. Truog WE, Sorenson G, Standaert TA, Redding GJ 1986 Effects of the thromboxane synthetase inhibitor, dazmegrel (UK 38,845), on pulmonary gas exchange and hemodynamics in neonatal sepsis. Pediatr Res 20:481-486

7. Gibson RL, Truog WE, Redding GJ 1988 Three types of gram positive bacteremia in piglets: thromboxane associated pulmonary hypotension. Pediatr Res 23.553-556

8. Truog WE, Gibson RL, Juul SE, Henderson WR, Redding GJ 1988 Neonatal group $\mathrm{B}$ streptococcal sepsis: effects of late treatment with dazmegrel. Pediatr Res 23:352-356

9. Tracey KJ, Beutler B, Lowry SF, Merryweather J, Wolpe S, Milsark IW, Hariri IJ, Fahey III JJ, Zentella A, Albert JD, Shires GT, Cerami A 1986 Shock and tissue injury induced by recombinant human cachectin. Science 234:470-473

10. Cifone MG, Alesse E, Reale M, Bologna M, Angeletti PU, Conti P 1986 Stimulatory effect of human recombinant tumor necrosis factor on $\mathrm{TxB}_{2}$ release by polymorphonuclear leukocytes and macrophages. Agents Actions 19:5-6

11. Kettelhut IC, Fiers W, Goldberg AL 1987 The toxic effects of tumor necrosis factor in vivo and their prevention by cyclooxygenase inhibitors. Proc Natl Acad Sci USA 84:4273-4277

12. Rendas A, Branthwaite M, Lennox S, Reid 1982 Response of the pulmonary circulation to acute hypoxia in the growing pig. J Appl Physiol 52:811-814

13. Truog WE, Standaert TA 1978 Non-rebreathing valve for spontaneously breathing or mechanically ventilated animals. J Appl Physiol 44:974-976

14. Wagner PD, Saltzman HA, West JB 1974 Measurement of continuous distributions of ventilation-perfusion ratios: theory. J Appl Physiol 36:588-599

15. Wagner PD, Saltzman HA, West JB 1974 Simultaneous measurement of eigh foreign gases in blood by gas chromatography. J Appl Physiol 36:600-606
16. Hlastala MP 1984 The multiple inert gas elimination technique. J Appl Physiol $56: 1-7$

17. Robertson HT, McKenna HP, Hlastala MP 1982 Influence of temperature and hemoglobin saturation of partition coefficients for those gases used for inert gas elimination studies. Physiologist 25:268(abstr)

18. Fitzpatrick FA 1982 A radioimmunoassay for thromboxane $B_{2}$. In: Lands WEM, Smith WL (eds) Prostaglandins and Arachidonate Metabolites. Methods of Enzymology. Academic Press, New York, pp 286-297

19. Geissler FT, Henderson WR 1988 Inability of aflatoxin $B_{1}$ to stimulate arachidonic acid metabolism in human polymorphonuclear and mononuclear leukocytes. Carcinogenesis 9:1135-1138

20. Wallenstein S, Zucker C, Fleiss J 1980 Some statistical methods useful in circulation research. Circulation Res 47:1-11

21. Lorenz RL, Fischer S, Wobers W, Wagner HA, Weber PC 1986 Effects on prostanoid formation and pharmacokinetics of dazmegrel (UK 38,485) a novel thromboxane synthase inhibitor in man. Biochem Pharmacol 35:761766

22. Furman BL, McKechnie K, Parratt JC 1984 Failure of drugs that selectively inhibit thromboxane synthesis to modify endotoxin shock in conscious rats. Br J Pharmacol 82:289-294

23. Catella F, Healy D, Lawson JA, Fitzgerald GA 1986 11-dehydrothromboxane $\mathrm{B}_{2}$ : a quantitative index of thromboxane $\mathrm{A}_{2}$ function in the human circulation. Proc Natl Acad Sci USA 82:5861-5865

24. Sugihara C, Goldberg RN, Hehre D, Bancalari A, Bancalari E 1987 Effects of cyclooxygenase and lipoxygenase products on pulmonary function in group B streptococcal sepsis. Pediatr Res 22:478-482

25. Rendas A, Branthwaite M, Reid L 1978 Growth of pulmonary circulation in normal pig-structural analysis and cardiopulmonary function. J Appl Physiol 45:806-817

26. Dehring DJ, Wismar B 1989 Intravascular macrophages in pulmonary capillaries of humans. Am Rev Respir Dis 139:1027-1029

27. Crocker SH, Eddy DO, Obenauf RN, Wismar BL, Lowery BD 1981 Bacteremia: host specific lung clearance and pulmonary failure. J Trauma 21:215220

28. Winkler GC 1988 Pulmonary intravascular macrophages in domestic animal species: Review of structural and functional properties. Am J Anat 181:217234

29. Warner AE, Molina RM, Brain JD 1987 Uptake of blood borne bacteria by pulmonary intravascular macrophages and consequent inflammatory response in sheep. Am Rev Respir Dis 136:683-690

30. Warner DE, Brain JD 1986 Intravascular pulmonary macrophages: a novel cell removes particles from blood. Am J Physiol 250:R728-R732

31. Escourrou PJL, Teisseire BP, Herigault RA, Vallez MO, Dupeyrat AJ, Gaultier C 1988 Mechanism of improvement in pulmonary gas exchange during growth in awake piglets. J Appl Physiol 65:1055-1061

32. Rowe RD, Sinclair JD, Kerr AR, Gage PW 1964 Duct flow and mitral regurgitation during changes in oxygenation in newborn swine. J Appl Physiol 19:1157-1162

33. Tracey KJ, Fong Y, Hesse DG, Manogue KR, Lee AT, Kuo GC, Lowry SF, Cerami A 1987 Anticachectin/TNF monoclonal antibodies prevent septic shock during lethal bacteremia. Nature 330:662-664

34. Stephens KE, Ishizaka A, Larrick JW, Raffin TA 1988 Tumor necrosis factor causes increased pulmonary permeability and edema. Am Rev Respir Dis 137:1364-1370

35. Johnson JE, Meyrick B, Jesmok G, Wickersham N, Brigham KL 1988 Infusion of recombinant human tumor necrosis factor alpha ( $\mathrm{rTNF}$ ) into sheep causes changes in pulmonary hemodynamics, pulmonary vascular permeability and leukocyte trafficking similar to those induced by endotoxin. Am Rev Respir Dis 137:391(abstr)

36. Custer JC, Hales C 1985 Influence of alveolar oxygen on pulmonary vasoconstriction in lambs vs. sheep. Am Rev Respir Dis 132:326-331

37. Cammussi G, Bussolino F, Salvidio G, Baglioni C 1987 Tumor necrosis factor/ cachectin stimulates peritoneal macrophages, polymorphonuclear neutrophils, and vascular endothelial cells to synthesize and release platelet-activating factor. J Exp Med 166:1390-1404

38. Dayer JM, Beutler B, Cerami A 1985 Cachectin/tumor necrosis factor stimulates collagenase and prostaglandin $\mathrm{E}_{2}$ production by human synovial cells and dermal fibroblasts. J Exp Med 162:2163-2168

39. Meyrick B, Jesmok C, Brigham KL 1988 Human recombinant tumor necrosis factor alpha (rTNF) causes cytotoxicity and prostanoid release from large and small lung vessel endothelial cells in culture. Am Rev Respir Dis 137:362(abstr)

40. Yoshimura K, Tod ML, Pier KG, Rubin LJ 1989 Role of venoconstriction in thromboxane-induced pulmonary hypertension and edema in lambs. $\mathbf{J}$ App Physiol 66:929-935

41. English BK, Burchett SK, English JD, Wilson C 1988 Production of lymphotoxin and tumor necrosis factor by human neonatal mononuclear cells. Pediatr Res 24:717-722

42. Martinet $\mathrm{X}$, Yamauchi K, Crystal RG 1988 Differential expression of the tumor necrosis factor/cachectin gene by blood and lung mononuclear phagocytes. Am Rev Respir Dis 138:659-665

43. Gibson RL, Redding GJ, Truog WE 1989 Tumor necrosis factor:potential mediator of group B streptococcal sepsis. Am Rev Respir Dis 139:A439(abstr) 